Check for updates

Cite this: RSC Adv., 2018, 8, 28746

\title{
Catalytic and anti-bacterial properties of biosynthesized silver nanoparticles using native inulin $\uparrow$
}

\author{
Wei Xu, (D)*ade Kunling Huang, ${ }^{a}$ Weiping Jin, ${ }^{b}$ Denglin Luo, ${ }^{c}$ Huan Liu, ${ }^{a}$ Yingying $L^{a}{ }^{a}$ \\ and Xinfang Liu ${ }^{a}$
}

Silver nanoparticles (Ag NPs) were green synthesized using native inulin as the reducing and capping agent with varied incubation temperatures, incubation times and $\mathrm{Ag}^{+}$concentrations. The biosynthesized Ag NPs were characterized using UV-visible spectroscopy, Field Emission Transmission Electron Microscopy (FETEM) and X-ray powder diffraction. The UV visible spectra of the Ag NPs revealed a characteristic surface plasmon resonance peak at $420 \mathrm{~nm}$. FE-TEM showed that the biosynthesized Ag NPs were spherically shaped and monodispersed nanoparticles. The sizes were $18.5 \pm 0.9 \mathrm{~nm}$ and $20.0 \pm 1.2 \mathrm{~nm}$ for the Ag NPs synthesized at $80{ }^{\circ} \mathrm{C}$ and $100{ }^{\circ} \mathrm{C}$ for $2 \mathrm{~h}$ using $0.1 \%$ inulin and $2 \mathrm{mM} \mathrm{Ag}^{+}$. Their PDIs were $0.180 \pm 0.05$ and $0.282 \pm 0.13$, respectively. Improving the incubation temperature, incubation time and silver nitrate concentration promoted Ag NP synthesis. The prepared Ag NPs were effective in the catalytic reduction of 4-NP and in inhibiting the growth of bacteria. The inhibition zone could reach $10.21 \pm 2.12 \mathrm{~mm}$ and $9.92 \pm$ $0.50 \mathrm{~mm}$ for Escherichia coli and Staphylococcus aureus. The kinetic rate constant $\left(k_{\mathrm{app}}\right)$ could reach $0.0113 \mathrm{~s}^{-1}$, and the maximum inhibitory zones were $10.21 \pm 2.12 \mathrm{~mm}$ and $9.92 \pm 0.50 \mathrm{~mm}$, respectively, for the two microorganisms. This biosynthesis illustrates that native inulin could be a potential candidate in the green fabrication of Ag NPs, and this is promising in catalytic and bacteriostatic fields.

Received 20th April 2018 Accepted 30th July 2018

DOI: $10.1039 / c 8 r a 03386 b$

rsc.li/rsc-advances

\section{Introduction}

Silver nanoparticles (Ag NPs), a type of noble metal nanoparticle, have emerged as promising antimicrobial agents, lightsensitive materials and sensing elements, and have been widely applied in the cosmetic, textile, medical and food industries. ${ }^{1-4}$ Recently, biosynthesis has been suggested as a potential alternative for Ag NP fabrication. Simplicity, cost effectiveness, high compatibility and low toxicity are common advantages during $\mathrm{Ag}$ NP formation. ${ }^{5-7}$ As a result, extensive interesting investigations have been conducted to green synthesize Ag NPs.

By masterly utilizing bioconversion, bacteria and fungi have been used for simple and eco-friendly synthesis methods. ${ }^{8}$ Besides this, active substances or plant extracts have been verified as ways to effectively biosynthesize Ag NPs. ${ }^{9,10}$ Coffea

${ }^{a}$ College of Life Science, Xinyang Normal University, Xinyang, 464000, China. E-mail: toxuwei1986@163.com

${ }^{b}$ College of Food Science and Engineering, Wuhan Polytechnic University, Wuhan, 430023, China

${ }^{c}$ College of Food and Bioengineering, Henan University of Science and Technology, Luoyan, 471023, China

${ }^{d}$ Tea Plant Biology Key Laboratory of Henan Province, Xinyang, 464000, China ${ }^{e}$ Institute for Conservation and Utilization of Agro-bioresources in Dabie Mountains, Xinyang, 464000, China

$\dagger$ Electronic supplementary information (ESI) available. See DOI: $10.1039 / \mathrm{c} 8 \mathrm{ra03386b}$ arabica seed extract, ${ }^{11}$ leaf extracts, ${ }^{12}$ tea extract ${ }^{13}$ and polyphenols $^{14}$ have been backed to biosynthesize Ag NPs. Polysaccharides, a kind of native biomacromolecule, have shown promise for Ag NP biosynthesis. Starch, ${ }^{15}$ guar gum and ${ }^{16}$ cellulose ${ }^{17}$ have been practiced to green synthesize Ag NPs. In our previous investigations, we have green synthetized Ag NPs using xanthan gum and found that the aggregation of Ag NPs was related to the xanthan gum conformation transition of denaturation and renaturation. The excellent antibacterial effect and catalytic capability of 4-nitrophenol reduction were further documented..$^{18}$ However, green synthesis of Ag NPs using native inulin has scarcely been reported.

Native inulin is a water soluble fructose-based polymer. As a dietary fiber from nature, inulin is a fructan varying in the degree of polymerization (DP) from 2 to 60 . It is found in various grains, fruits and vegetables. Native inulin is usually extracted from chicory or Jerusalem artichokes. ${ }^{19}$ It has been reported that inulin has many health benefits, including regulating blood glucose. ${ }^{20}$ Due to the excellent water-holding capacity of the gel, it is commonly used as a modifier and functional ingredient in the food field. ${ }^{21}$ In this paper, we explore the biosynthesis of Ag NPs using native inulin. The catalytic and antibacterial properties were further investigated. This endeavor provided a feasible method for Ag NP biosynthesis with excellent antibacterial and catalytic properties which may facilitate their use in medical, food, and biological applications. 


\section{Materials and methods}

\subsection{Materials}

Native inulin (DP 2-60) was obtained from the Cosucra Company (Belgium). Silver nitrate, 4-nitro-phenol (4-NP), sodium borohydride and other chemical reagents were purchased from commercial sources in China. Their solutions were prepared using ultrapure water from a Millipore (Millipore, Milford, MA, USA) Milli-Q water purification system.

\subsection{Synthesis of the silver nanoparticles}

For the synthesis of the silver nanoparticles, $0.1 \mathrm{mg}$ of inulin was dissolved in $100 \mathrm{~mL}$ of ultrapure water under constant stirring (84-1A, Shanghai meiyingpu instrument Co. LTD) for $2 \mathrm{~h}$ to obtain a $0.1 \%(\mathrm{w} / \mathrm{v})$ solution. Subsequently, $\mathrm{AgNO}_{3}$ was added into the inulin solutions to get the final concentrations of $1 \mathrm{mM}, 2 \mathrm{mM}$ and $3 \mathrm{mM}$. The reaction mixtures were incubated for the time periods of $1 \mathrm{~h}, 2 \mathrm{~h}$ and $3 \mathrm{~h}$ at $80^{\circ} \mathrm{C}$ and $100^{\circ} \mathrm{C}$ under dark conditions with stirring.

\subsection{Characterization}

UV-visible spectroscopy (UV-vis) was performed using a UV/VIS/ NIR Spectrometer (Lambda950, United States) as a function of temperature during the synthesis of the Ag NPs. The control was run as only $0.1 \%$ of the corresponding polysaccharide without a reducing agent. The hydrate particle size and zeta potential were measured using a commercial laser light scattering instrument (Zetasizer NanoZS, Malvern Instruments, United Kingdom) at $25{ }^{\circ} \mathrm{C}$. Each sample was measured three times. A drop of the Ag NP colloidal solution was dispensed directly onto a carbon-coated copper grid and dried completely in a vacuum desiccator. Then the pictures of the prepared samples were obtained using a Field Emission Transmission Electron Microscope (FE-TEM) (G2 F20S, Hitachi, United States). The composition was also examined using energy-dispersive X-ray spectroscopy (EDX) with the FE-TEM. X-ray powder diffraction (XRD) was scanned over the range $2 \theta 5-85^{\circ}$ using $\mathrm{Cu} \mathrm{K} \alpha$ radiation with a scanning rate of $0.5^{\circ} \mathrm{min}^{-1}, 40 \mathrm{kV}$ and $30 \mathrm{~mA}$ (Smartlab9, Japan).

\subsection{Catalytic reduction of 4-NP}

The catalytic 4-NP reduction was carried out in the same manner as in our previous reports. ${ }^{22,23}$ Briefly, $10 \mathrm{~mL}$ of fresh $\mathrm{NaBH}_{4}$ aqueous solution $(0.2 \mathrm{M})$ was mixed with $10 \mu \mathrm{L}$ of aqueous Ag NPs. Subsequently, $1 \mathrm{~mL}$ of 4 -NP solution $\left(2 \times 10^{-3}\right.$ M) was added into $1 \mathrm{~mL}$ of the above mixture. The
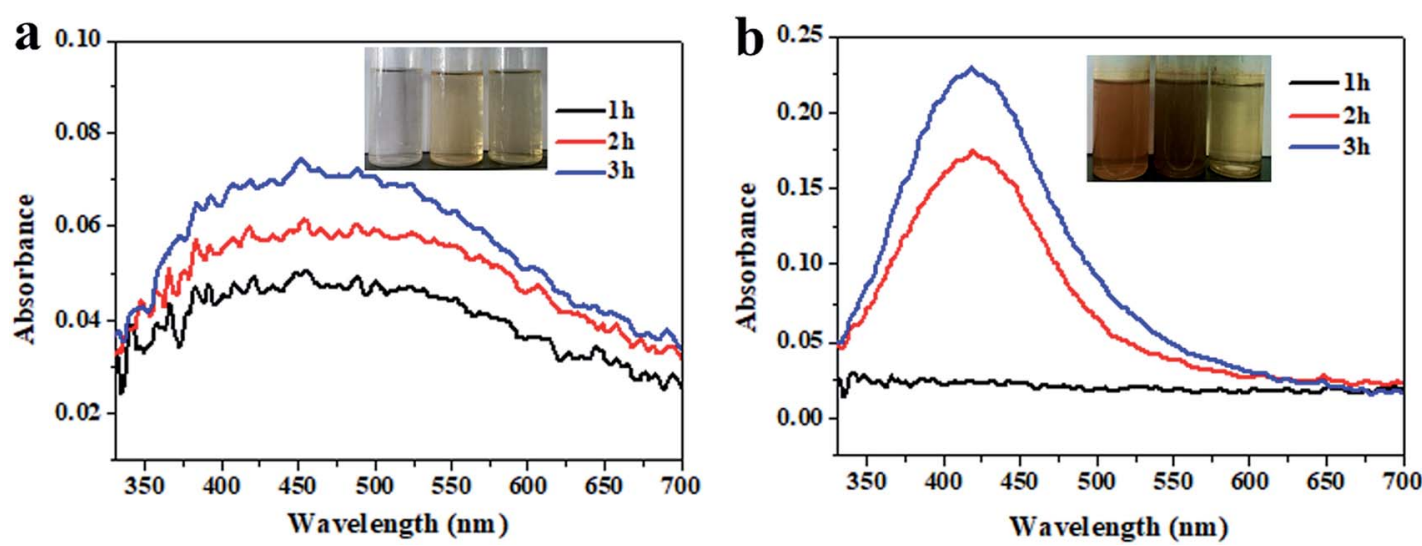

Fig. 1 UV-vis spectra of the Ag NPs as a function of reaction time incubated at $80{ }^{\circ} \mathrm{C}$ (a) and $100{ }^{\circ} \mathrm{C}$ (b) with $2 \mathrm{mM} \mathrm{Ag}^{+}$and $0.1 \%$ inulin.
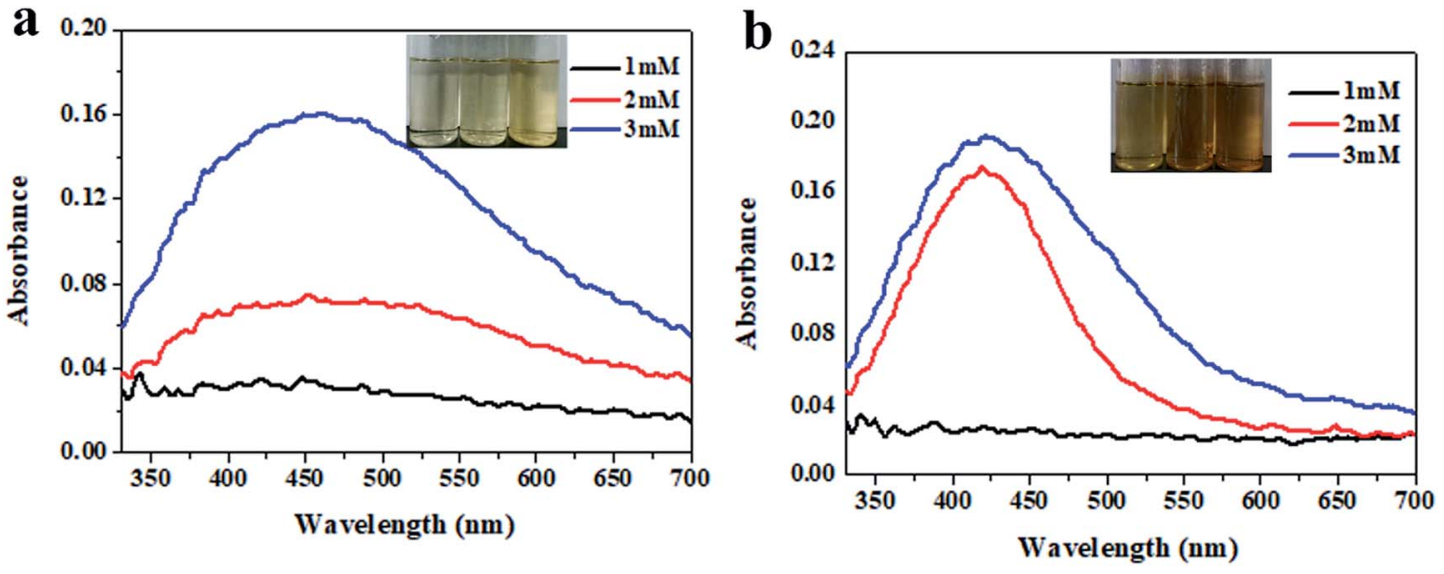

Fig. 2 UV-vis spectra of the Ag NPs as a function of $\mathrm{Ag}^{+}$concentration incubated at $80{ }^{\circ} \mathrm{C}$ (a) and $100{ }^{\circ} \mathrm{C}$ (b) for $2 \mathrm{~h}$ with $0.1 \%$ inulin. 
concentrations of 4-NP and $\mathrm{NaBH}_{4}$ in the reaction solution were finally $2 \times 10^{-4} \mathrm{M}$ and $0.1 \mathrm{M}$, respectively. The reaction was monitored by measuring the absorbance at $400 \mathrm{~nm}$ using a UV/ VIS/NIR Spectrometer (Lambda950, United States).

\subsection{Antibacterial assay}

The green synthesized Ag NPs were tested for antimicrobial activity via the well diffusion method and modified dilution method against pathogenic bacteria, including Gram-negative Escherichia coli and Gram-positive Staphylococcus aureus. Briefly, filter paper discs (6 mm) were soaked in the formed $\mathrm{Ag}$ NP solution for $15 \mathrm{~min}$, and then placed on the inoculated plates that cultured Escherichia coli and Staphylococcus aureus. The zones of inhibition were measured after incubation at $37^{\circ} \mathrm{C}$ for $24 \mathrm{~h}$. The dilution method was conducted by adding different volumes onto the inoculated plates that cultured Escherichia coli and Staphylococcus aureus. Then their growth after $24 \mathrm{~h}$ of incubation was observed.

\section{Results and discussion}

\subsection{Effect of heating time on the Ag NP synthesis}

In this study, native inulin was used as the reducing and stabilizing agent for the Ag NP synthesis. As shown in Fig. 1, the characteristic UV-vis spectra indicated that the Ag NPs had been green biosynthesized. The visual observation of the solution changing to a dark brownish yellow color further indicated the formation of Ag NPs, as this has been found in the results of other publications during Ag NP synthesis. ${ }^{24}$ The absorption spectrum showed an intense band at around $420 \mathrm{~nm}$ that was
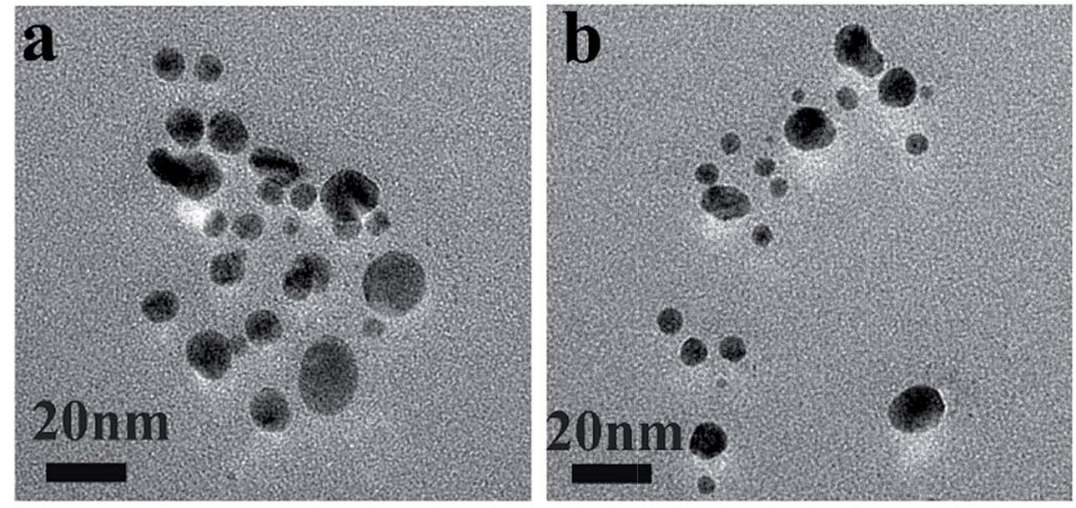

c

\begin{tabular}{|c|c|c|c|}
\hline & Average Size (nm) & PDI & Zeta $(\mathrm{mV})$ \\
\hline Ag80 NPs & $12.5 \pm 0.6$ & $0.185 \pm 0.07$ & $-0.95 \pm 0.12$ \\
\hline Ag100 NPs & $9.8 \pm 1.5$ & $0.28 \pm 0.14$ & $-0.18 \pm 0.05$ \\
\hline
\end{tabular}
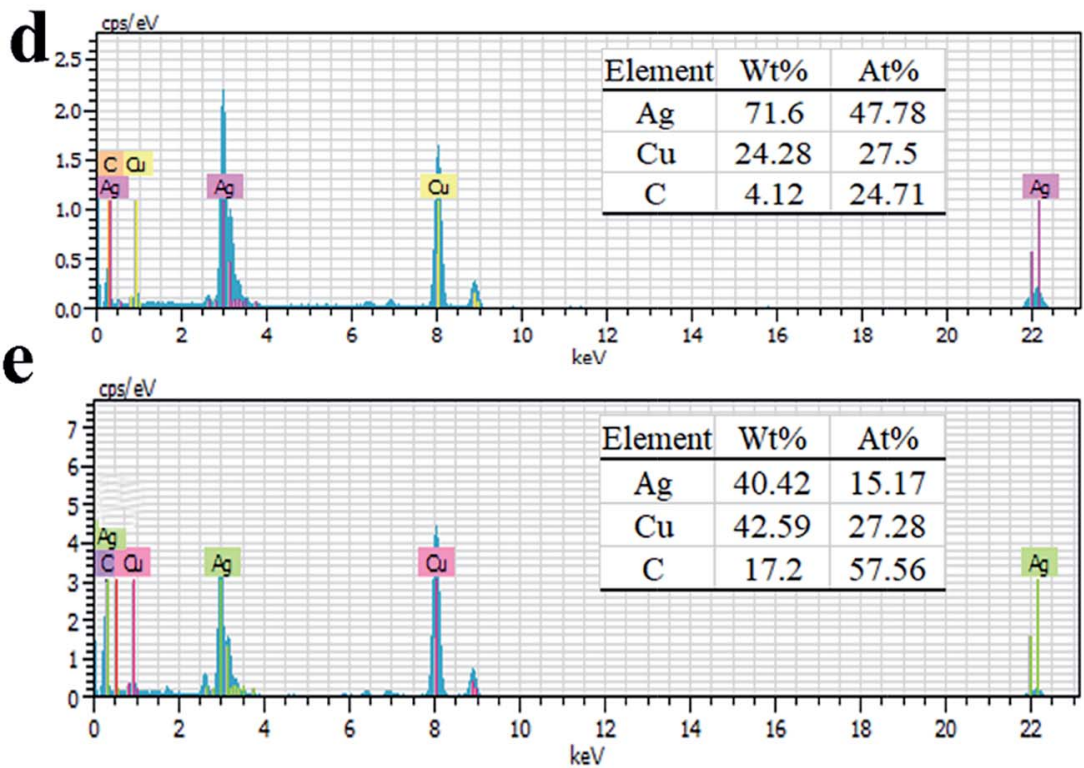

Fig. 3 FE-TEM images ( $a$ and b), size, PDI, zeta potential (c) and EDX ( $d$ and e) of Ag NPs synthesized at $80^{\circ} \mathrm{C}(\mathrm{a}$ and $d)$ and $100{ }^{\circ} \mathrm{C}(\mathrm{b}$ and e) for $2 \mathrm{~h}$ using $0.1 \%$ inulin and $2 \mathrm{mM} \mathrm{Ag}^{+}$. 
identified as a "surface Plasmon resonance band" and ascribed to the excitation of free electrons in the Ag NPs. Meanwhile, a higher incubation temperature promoted the reduction of the $\mathrm{Ag}$ NPs. The progressive absorption illustrated the gradual evolution of the Ag NP synthesis as the heating time increased. Inulin, classifying as either an oligo- or polysaccharide, belongs to the fructan carbohydrate subgroup. During the heating process, the increased number of hydroxyl groups on the inulin chain causes the active reduction of $\mathrm{Ag}^{+}$to $\mathrm{Ag}^{0}$.

\subsection{Effect of $\mathrm{Ag}^{+}$concentration on the $\mathrm{Ag} \mathrm{NP}$ synthesis}

The effect of the $\mathrm{Ag}^{+}$concentration ( $1 \mathrm{mM}, 2 \mathrm{mM}$ and $3 \mathrm{mM}$ ) on the synthesis of the $\mathrm{Ag}$ NPs was investigated with $0.1 \%$ inulin after heating for $2 \mathrm{~h}$ at $80{ }^{\circ} \mathrm{C}$ and $100{ }^{\circ} \mathrm{C}$ (Fig. 2). Fig. 2 displays similar phenomena to Fig. 1. Obviously, the increasing brown colour change of the inset illustrates the easy synthesis of the $\mathrm{Ag}$ NPs with a higher $\mathrm{Ag}^{+}$concentration. The increased absorption intensity with an increase in $\mathrm{Ag}^{+}$concentration and a high incubation temperature simultaneously certify an enhanced reduction of $\mathrm{Ag}^{+}$. It was noted that approximately $3 \mathrm{mM} \mathrm{Ag}^{+}$needed to be provided at $80^{\circ} \mathrm{C}$ incubation. Comparatively, the phenomenon of the surface Plasmon resonance band was obvious when the $\mathrm{Ag}^{+}$ concentration was $3 \mathrm{mM}$ and incubation was at $100{ }^{\circ} \mathrm{C}$. After formation, the Ag NPs get embedded and stabilized within the inulin matrix as with other polysaccharides. ${ }^{25}$ It has been illustrated that Ag NPs can be fabricated using glucose as the reducing agent, and impregnated into cellulose, microcrystalline cellulose, carboxymethyl cellulose and chitosan. ${ }^{26}$

\subsection{Morphology of the synthesized Ag NPs}

The morphology of the various Ag NPs fabricated using inulin was further investigate using FE-TEM. The results (Fig. 3a) clearly demonstrate that the Ag NPs were biosynthesized and exhibited an inerratic spherical appearance. It was noted that the inulin-based Ag NPs displayed excellent dispensability (Fig. S1 $\dagger$ ). When the incubation temperature increased from $80{ }^{\circ} \mathrm{C}$ to $100{ }^{\circ} \mathrm{C}$, much more $\mathrm{Ag}$ NPs were synthesized. More interestingly, the size of the $\mathrm{Ag}$ NPs nearly remained unchanged. The hydrate particle sizes were $12.5 \pm 0.6 \mathrm{~nm}$ and $9.8 \pm 1.5 \mathrm{~nm}$ for the $\mathrm{Ag}$ NPs synthesized at $80^{\circ} \mathrm{C}$ and $100{ }^{\circ} \mathrm{C}$, respectively, for $2 \mathrm{~h}$ using $0.1 \%$ inulin and $2 \mathrm{mM} \mathrm{Ag}^{+}$. These results were in agreement with the particle size distribution analysis of the TEM image (Fig. S2 $\dagger$ ). The PDIs were $0.185 \pm 0.07$ and $0.28 \pm 0.14$, respectively. The low PDIs illustrate the excellent distribution of the fabricated Ag NPs. This phenomenon may relate to the structure of the inulin matrix. In the same way as when treated with a thermal process, the exposed external hydroxyl groups exert the reduction effect and further combine with the Ag NPs, endowing them with their high stability. The EDX spectra further confirms the fabrication of the Ag NPs based on native inulin (Fig. 3d and e).

\subsection{XRD analysis of the inulin-based Ag NPs}

As Fig. 4 shows, inulin was amorphous. This well coincided with previous studies. ${ }^{27}$ Meanwhile, the inulin-based Ag NPs showed distinctive characteristic diffraction peaks at $38^{\circ}$ and $44^{\circ}$. These

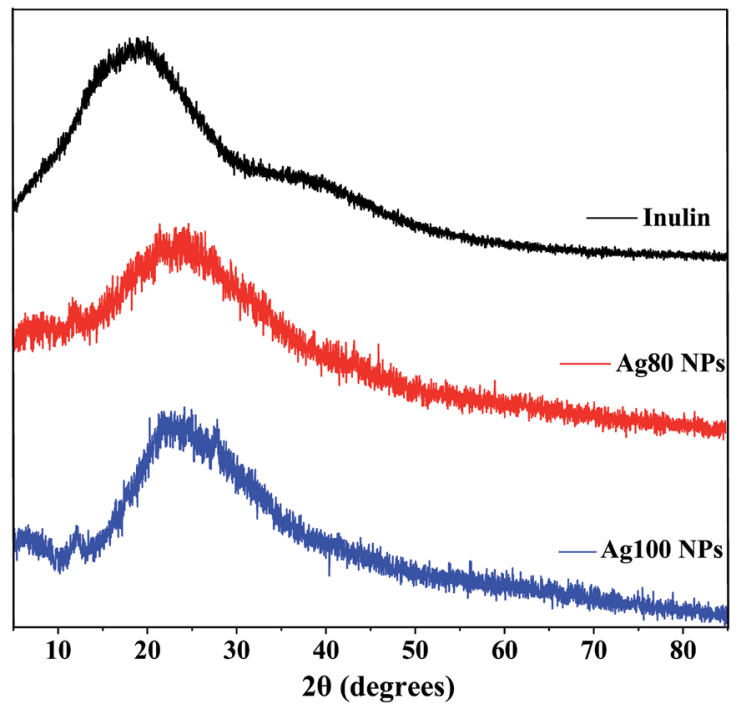

Fig. 4 XRD analysis of inulin and the Ag NPs synthesized at $80^{\circ} \mathrm{C}$ and $100{ }^{\circ} \mathrm{C}$ for $2 \mathrm{~h}$ using $0.1 \%$ inulin and $2 \mathrm{mM} \mathrm{Ag}^{+}$.

typical diffraction peaks possibly illustrate the formation of a face centered cubic structure. It was noted that the distinctive characteristic diffraction peaks were not intense enough. Additionally, strong peaks at $12.1^{\circ}$ appeared during the inulinbased Ag NP synthesis. This may have been affected by the crystallization behavior of inulin during the freeze drying process. Furthermore, it was found that the diffuse peak of the inulin-based Ag NPs shifted as compared with that of inulin, which further confirmed the interaction between inulin and the Ag NPs during biosynthesis.

\subsection{Catalytic behavior for the reduction of 4-NP}

To compare the catalytic efficiency of the inulin-based Ag NPs, their catalytic behaviors were examined through the model reaction of 4-NP reduced by $\mathrm{NaBH}_{4}$. Kinetic rate constant $\left(k_{\text {app }}\right)$ values were calculated and were used to evaluate the catalytic behavior. The pseudo-first-order kinetics are often described as $\ln \left(C_{t} / C_{0}\right)=-k_{\text {app }} t$, where $C_{t}$ is the concentration of 4-NP at time $t, C_{0}$ is the original concentration of $4-\mathrm{NP}$, and $k_{\text {app }}$ is the degradation rate (Fig. 5). By comparing the $k_{\text {app }}$ values of the green, synthetic Ag NPs at different conditions, it was easily found that $k_{\text {app }}$ continuously increased as the incubation temperature increased and the time increased. When the incubation temperature was $80^{\circ} \mathrm{C}$ and silver nitrate was at $2 \mathrm{mM}$, the $k_{\text {app }}$ values were $0.0074 \mathrm{~s}^{-1}, 0.0086 \mathrm{~s}^{-1}$, and $0.0093 \mathrm{~s}^{-1}$ when the incubation time was $1 \mathrm{~h}, 2 \mathrm{~h}$ and $3 \mathrm{~h}$ accordingly. In comparison, the value increased to $0.0085 \mathrm{~s}^{-1}, 0.0100 \mathrm{~s}^{-1}$ and $0.0113 \mathrm{~s}^{-1}$ for the Ag100 NPs, respectively. Even so, the $k_{\text {app }}$ was noted to be more significantly affected by the concentration of silver nitrate. The $k_{\text {app }}$ values of the Ag80 NPs were $0.0043 \mathrm{~s}^{-1}$ and $0.0113 \mathrm{~s}^{-1}$ when $1 \mathrm{mM}$ and $2 \mathrm{mM} \mathrm{Ag}^{+}$was provided. Meanwhile, the catalytic behavior clearly accelerated for the Ag100 NPs. The $k_{\text {app }}$ accordingly increased to $0.007 \mathrm{~s}^{-1}$ and $0.0115 \mathrm{~s}^{-1}$. This confirmed that all of the final conversion of 4-NP was below $4.5 \%$ (Fig. S3†). The high $k_{\text {app }}$ was nearly equivalent to that of silver- 

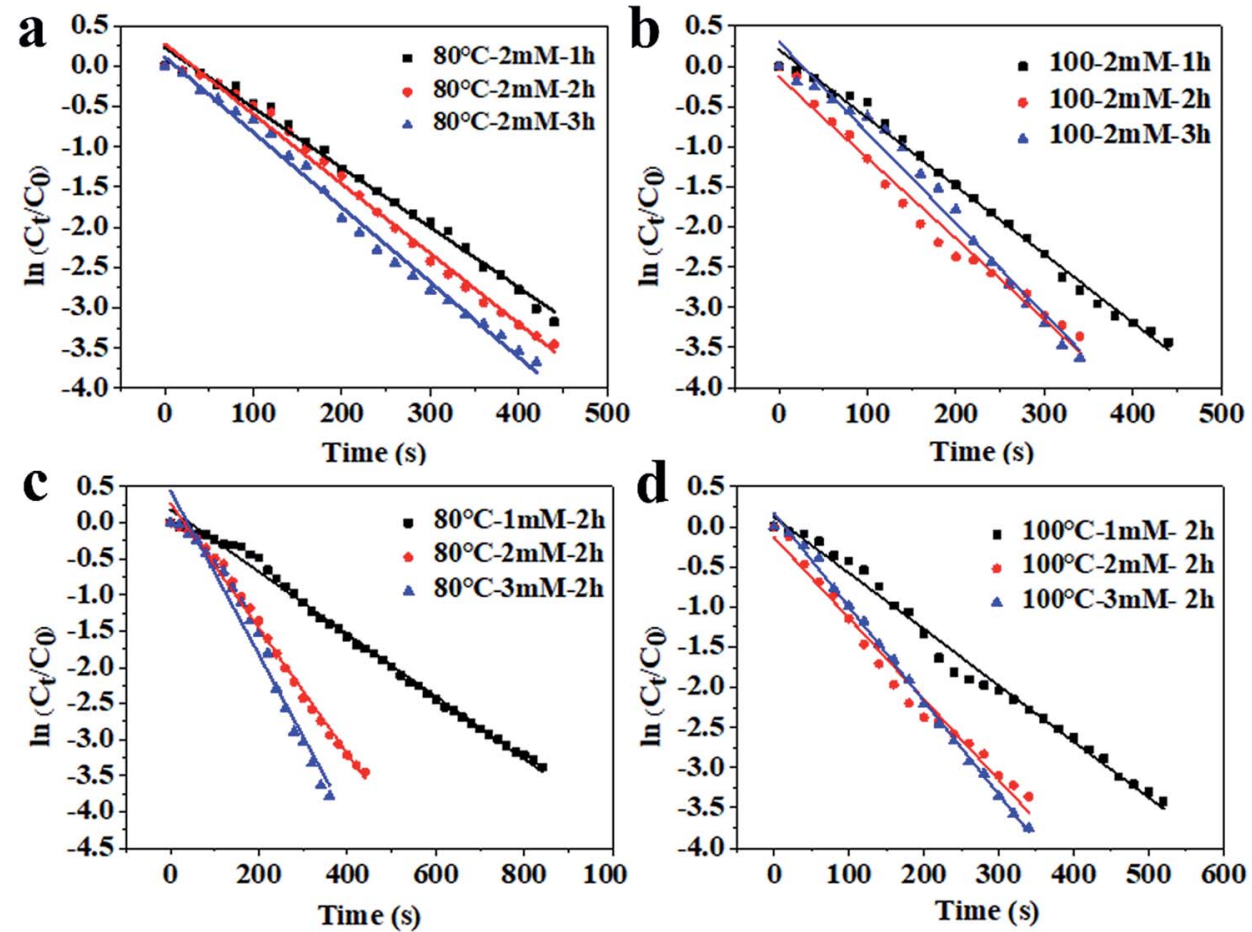

Fig. 5 The relationship between $\ln \left(C_{t} / C_{0}\right)$ and reaction time of the inulin-based Ag NPs synthesized at $80{ }^{\circ} \mathrm{C}(\mathrm{a}$ and $\mathrm{c})$ and $100{ }^{\circ} \mathrm{C}(\mathrm{b}$ and $\mathrm{d})$ with different $\mathrm{Ag}^{+}$concentrations.

deposited magnetic nanoparticles $\left(1.5 \times 10^{-2} \mathrm{~s}\right) .^{28}$ Compared with our published paper, the catalytic behavior equally matched that of the Ag NPs that were green biosynthesized using soluble green tea powder, in which the $k_{\text {app }}$ values were $0.00918 \mathrm{~s}^{-1}$, $0.00931 \mathrm{~s}^{-1}$ and $0.00941 \mathrm{~s}^{-1}$ when the reaction times were $20 \mathrm{~min}, 40 \mathrm{~min}$ and $60 \mathrm{~min}$, respectively (Fig. 6). ${ }^{29}$ As in the previous study, $k_{\text {app }}$ mainly depended on the specific surface area and quantity of the Ag NPs. ${ }^{30}$ This well coincided with the $\mathrm{Ag}$ NPs size and distribution shown in Fig. 1-3.

\subsection{Antibacterial properties of the inulin-based Ag NPs}

As Fig. 7 and Table 1 show, the antibacterial activity of the inulin-based $\mathrm{Ag}$ NPs was determined for the preparation conditions. The higher the incubation temperature and $\mathrm{Ag}^{+}$ concentration, the higher the antimicrobial activity that was exhibited. When prepared at $80{ }^{\circ} \mathrm{C}$ with $2 \mathrm{mM} \mathrm{Ag}^{+}$, the zones of inhibition for Escherichia coli and Staphylococcus aureus were $8.10 \pm 0.20 \mathrm{~mm}$ and $8.11 \pm 0.39 \mathrm{~mm}$, respectively. Meanwhile for the Ag100 NPs, the inhibition zones increased to $9.93 \pm$ $0.21 \mathrm{~mm}$ and $8.74 \pm 0.36 \mathrm{~mm}$. When $3 \mathrm{mM} \mathrm{Ag}^{+}$was used, the values further improved to $10.21 \pm 2.12 \mathrm{~mm}$ and $9.92 \pm 0.50$ $\mathrm{mm}$. This phenomenon may have resulted from the increasing concentration of Ag NPs as the incubation temperature and $\mathrm{Ag}^{+}$ concentration increased. It was also noted that the antimicrobial activity was higher against Escherichia coli than it was against Staphylococcus aureus. This similar phenomenon was also backed by Jeeva. They found that the antibacterial activity of metallic silver nanoparticles synthesized using leaf extracts of
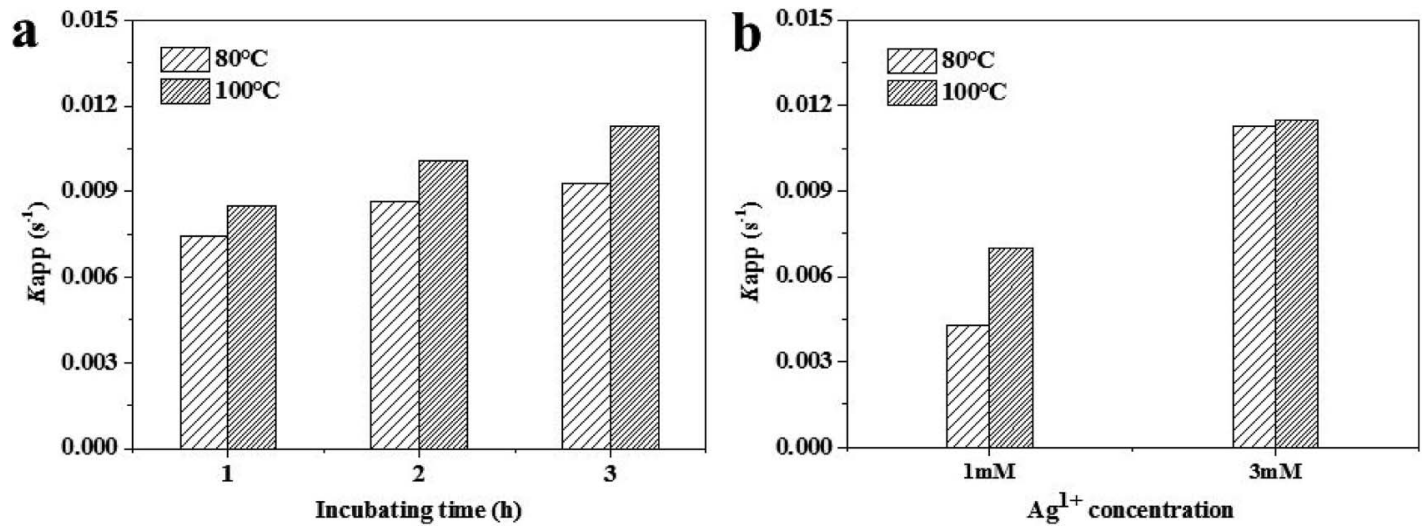

Fig. 6 Apparent rate constants, $k_{a p p}$, of the inulin-based Ag NPs synthesized at $80{ }^{\circ} \mathrm{C}$ and $100{ }^{\circ} \mathrm{C}$ with different $\mathrm{Ag}^{+}$concentrations. 

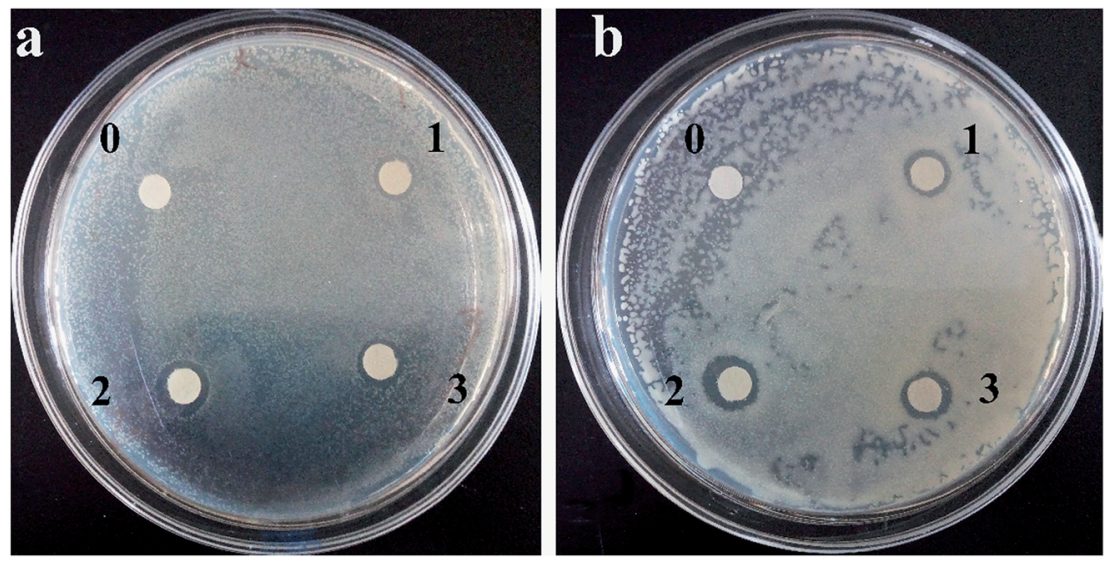

Fig. 7 Zone of inhibition of the inulin-based Ag NPs against Escherichia coli (a) and Staphylococcus aureus (b). 0: Inulin solution; 1: Ag NPs formed at $80^{\circ} \mathrm{C}$ using $2 \mathrm{mM} \mathrm{Ag}^{+} ; 2$ : Ag NPs formed at $100^{\circ} \mathrm{C}$ using $2 \mathrm{mM} \mathrm{Ag}^{+} ; 3$ : Ag NPs formed at $100{ }^{\circ} \mathrm{C}$ using $3 \mathrm{mM} \mathrm{Ag}^{+}$. The reaction time was $2 \mathrm{~h}$ and inulin was at $0.1 \%$.

Table 1 Zone of inhibition obtained via the disc diffusion method ${ }^{a}$

\begin{tabular}{lll}
\hline Components & Escherichia coli $(\mathrm{mm})$ & $\begin{array}{l}\text { Staphylococcus } \\
\text { aureus }(\mathrm{mm})\end{array}$ \\
\hline Inulin $(0.1 \%)$ & $\mathrm{NZ}$ & $\mathrm{NZ}$ \\
Sample 1 & $8.10 \pm 0.20 \mathrm{c}$ & $8.11 \pm 0.39 \mathrm{c}$ \\
Sample 2 & $9.93 \pm 0.21 \mathrm{~b}$ & $8.74 \pm 0.36 \mathrm{c}$ \\
Sample 3 & $10.21 \pm 2.12 \mathrm{a}$ & $9.92 \pm 0.50 \mathrm{~b}$
\end{tabular}

${ }^{a} \mathrm{NZ}$ represents no result through visual interpretation. The samples were the same as in Fig. 7. Different letters indicate significant differences $(p \leq 0.05)$.

Caesalpinia coriaria displayed a much higher antimicrobial activity against Escherichia coli. ${ }^{31}$ In comparison, for our published xanthan gum-based Ag NPs, the antibacterial activity related to the conformation of xanthan, and displayed relatively low bacteriostatic ability $(S$. aureus was about $12.3 \mathrm{~mm}$, and it was $10.7 \mathrm{~mm}$ for $E$. coli). This also confirms that the antibacterial activities are determined by the employed polysaccharide. ${ }^{18}$ The different antibacterial behaviors may be related to the adsorption to the cell membrane that is determined by the stabilizer. Fig. 8 further verified, through visual interpretation, the antibacterial behavior of inulin-based $\mathrm{Ag}$ NPs. The antibacterial capacities well agreed with Fig. 7 and Table 1 . When the addition was $200 \mu \mathrm{L}$, the inhibition rates could reach $98 \pm 3 \%$ for Escherichia coli when the Ag NPs were formed at $100{ }^{\circ} \mathrm{C}$ using $3 \mathrm{mM} \mathrm{Ag}^{+}$. Meanwhile for Staphylococcus aureus, the inhibition rates were $88 \pm 1.5 \%$. These results well coincided with the results of Fig. 7. The antibacterial properties of the inulin-based Ag NPs may be caused by how efficiently the NPs get attached to the cell membrane and penetrate inside the bacteria. The permeability of the cell membrane was ultimately changed, or the Ag NPs interacted with protein or DNA, which further led to bacteria death.
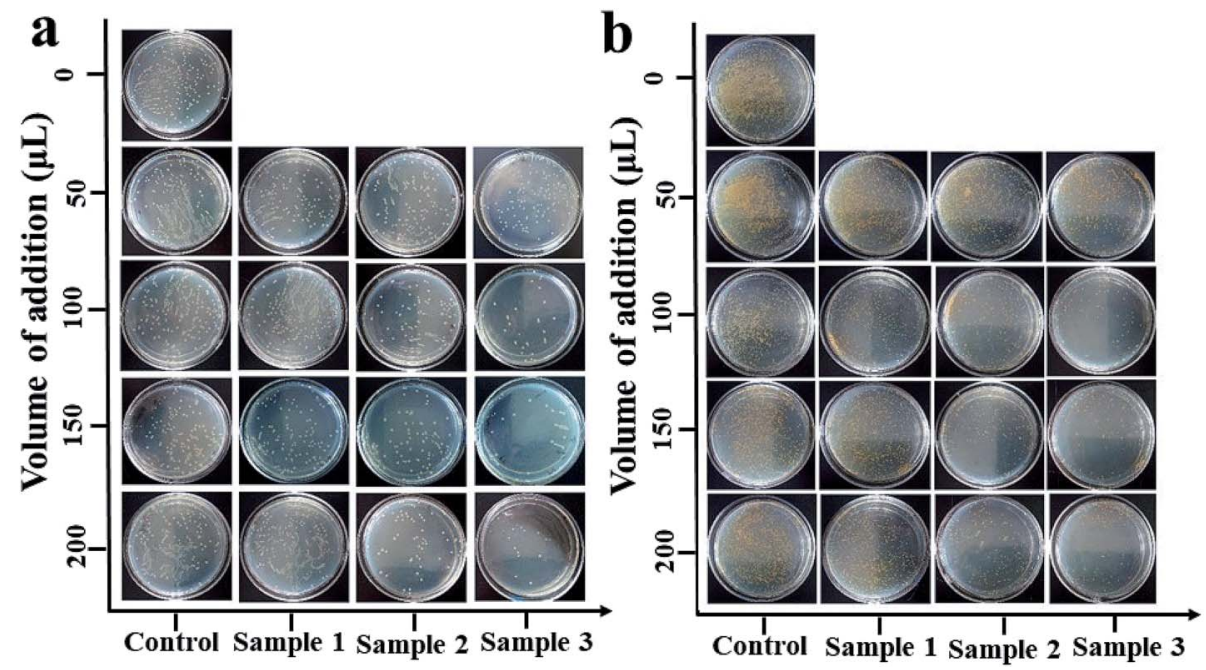

Fig. 8 Antibacterial behavior of inulin-based Ag NPs against Escherichia coli (a) and Staphylococcus aureus (b). Control: without addition; sample 1: Ag NPs formed at $80^{\circ} \mathrm{C}$ using $2 \mathrm{mM} \mathrm{Ag}^{+}$; sample 2: Ag NPs formed at $100^{\circ} \mathrm{C}$ using $2 \mathrm{mM} \mathrm{Ag}^{+}$; sample 3: Ag NPs formed at $100{ }^{\circ} \mathrm{C}$ using $3 \mathrm{mM} \mathrm{Ag}^{+}$. The reaction time was $2 \mathrm{~h}$ and inulin was at $0.1 \%$. 


\section{Conclusions}

Water dispersible Ag NPs with excellent dispersion were biosynthesized using inulin through a one spot thermal incubation. The synthesized Ag NPs exhibited an inerratic spherical appearance. When the incubation temperature was $80{ }^{\circ} \mathrm{C}$ and the $\mathrm{Ag}^{+}$concentration was $2 \mathrm{mM}$, the $k_{\text {app }}$ values were 0.0074 $\mathrm{s}^{-1}, 0.0086 \mathrm{~s}^{-1}$ and $0.0093 \mathrm{~s}^{-1}$ when the incubation times were $1 \mathrm{~h}, 2 \mathrm{~h}$ and $3 \mathrm{~h}$ accordingly. In comparison, the values increased to $0.0085 \mathrm{~s}^{-1}, 0.0100 \mathrm{~s}^{-1}$ and $0.0113 \mathrm{~s}^{-1}$ for the Ag100 NPs, respectively. A bacteriostatic test illustrated that the fabricated Ag NPs had antimicrobial activity against Escherichia coli and Staphylococcus aureus. The maximum inhibitory zones reached $10.21 \pm 2.12 \mathrm{~mm}$ and $9.92 \pm 0.50 \mathrm{~mm}$, respectively. These results verified that native inulin could be effective as a reducing agent and stabilizer for Ag NP fabrication. Their antibacterial and catalytic activities confirmed that inulin-based $\mathrm{Ag}$ NPs may be good candidates for use in biological and chemical fields.

\section{Conflicts of interest}

There are no conflicts to declare.

\section{Acknowledgements}

This work was financially supported by the National Natural Science Foundation of China (Grant No. 31701647), the Natural Science Foundation of Henan province (Grant No. 162300410229), and the Nanhu Scholars Program for Young Scholars of XYNU.

\section{References}

1 Z. M. Mahdieh, S. Shekarriz, F. A. Taromi and M. Montazer, Cellulose, 2018, 25, 2355-2366.

2 S. K. Srikar, D. D. Giri, B. P. Dan, P. K. Mishra and S. N. Upadhyay, Green Sustainable Chem., 2016, 6, 34-56.

3 Y. Shao, C. Wu, T. Wu, S. Chen, T. Ding, X. Ye and Y. Hu, Int.

J. Biol. Macromol., 2018, 111, 1281-1292.

4 I. Ghiuță, D. Cristea, C. Croitoru, J. Kost, R. Wenkert, I. Vyrides, A. Anayiotose and D. Munteanu, Appl. Surf. Sci., 2018, 438, 66-73.

5 I. Rasaee, M. Ghannadnia and S. Baghshahi, Microporous Mesoporous Mater., 2018, 264, 240-247.

6 S. C. G. KirubaDaniel, L. AlbinaNirupa Julius and S. SivaGorthi, Sens. Actuators, B, 2017, 238, 641-650.

7 T. Rasheed, M. Bilal, H. M. N. Iqbal and C. L. Li, Colloids Surf., B, 2017, 158, 408-514.
8 I. Aiad, M. I. Marzouk, S. A. Shaker, N. E. Ebrahim, A. A. AbdElaal and S. M. Tawfik, J. Mol. Liq., 2017, 243, 572-583.

9 M. T. Moustafa, Water Science, 2017, 31, 164-176.

10 A. Barapatre, K. R. Aadil and H. Jha, Bioresour. Bioprocess., 2016, 3, 8.

11 V. Dhand, L. Soumya, S. Bharadwaj, S. Chakra, D. Bhatt and B. Sreedhar, Mater. Sci. Eng., C, 2016, 58, 36-43.

12 L. Wang, Y. Wu, J. Xie, S. Wu and Z. Wu, Mater. Sci. Eng., C, 2018, 86, 1-8.

13 M. Sökmen, S. Y. Alomar, C. Albay and G. Serdar, J. Alloys Compd., 2017, 725, 190-198.

14 S. Ferraris, M. Miola, A. Cochis, B. Azzimonti, L. Rimondini, E. Prenesti and E. Vernè, Appl. Surf. Sci., 2016, 396, 461-470.

15 J. Jung, G. M. Raghavendra, D. Kim and J. Seo, Int. J. Biol. Macromol., 2017, 107, 2285-2290.

16 E. S. Abdel-Halim, M. H. El-Rafie and S. S. Al-Deyab, Carbohydr. Polym., 2011, 85, 692-697.

17 A. Salama, Environmental Nanotechnology, Monitoring \& Management, 2017, 8, 228-232.

18 W. Xu, W. Jin, L. Lin, C. Zhang, Z. Li, Y. Li, R. Song and B. Li, Carbohydr. Polym., 2014, 101, 961-967.

19 D. Luo, L. Yun, B. Xu, G. Ren, P. Li, L. Xuan, S. Han and J. Liu, Food Chem., 2017, 229, 35-43.

20 M. Shoaib, A. Shehzad, M. Omar, A. Rakha, H. Raza, H. R. Sharif, A. Shakeel, A. Ansari and S. Niazi, Carbohydr. Polym., 2016, 147, 444-454.

21 D. Meyer, S. Bayarri, A. Tárrega and E. Costell, Food Hydrocolloids, 2011, 25, 1881-1890.

22 X. An, Y. Long and Y. Ni, Carbohydr. Polym., 2017, 156, 253258.

23 J. Xu, T. Zhou, L. Jia, X. Shen, X. Li, H. Li, Z. Xu and J. Cao, J. Nanopart. Res., 2017, 19, 103.

24 R. M. El-Shishtawy, A. M. Asiri, N. A. M. Abdelwahed and M. M. Al-Otaibi, Cellulose, 2011, 18, 75-82.

25 D. Guo, G. Liu, X. Li, X. Tang, J. Zhang, X. Zhu and S. Jiang, J. Bionanosci., 2015, 9, 325-329.

26 A. G. Hassabo, A. A. Nada, H. M. Ibrahim and N. Y. AbouZeid, Carbohydr. Polym., 2015, 122, 343-350.

27 P. Glibowski and S. Pikus, Carbohydr. Polym., 2011, 83, 635639.

28 K. S. Shin, J. Y. Choi, S. P. Chan, H. J. Jang and K. Kim, Catal. Lett., 2009, 133, 1-7.

29 W. Xu, Y. P. Fan, X. F. Liu, D. L. Luo, H. Liu and N. N. Yang, Mater. Res. Express, 2018, 5, 1-8.

30 Y. Chi, J. Tu, M. Wang, X. Li and Z. Zhao, J. Colloid Interface Sci., 2014, 423, 54-59.

31 K. Jeeva, M. Thiyagarajan, V. Elangovan, N. Geetha and P. Venkatachalam, Ind. Crops Prod., 2014, 52, 714-720. 